Research Article

\title{
Synthesis and Characterization of Semicrystalline Polyimides Containing Bridged Linkages
}

\author{
Min Chao $\mathbb{D}^{1,2}$ \\ ${ }^{1}$ Polymer Materials \& Engineering Department, School of Materials Science \& Engineering, Chang'an University, \\ Xi'an 710064, China \\ ${ }^{2}$ Institute of Polymer Materials, Chang'an University, Xi'an 710064, China \\ Correspondence should be addressed to Min Chao; chaominchd@163.com
}

Received 7 March 2018; Revised 24 May 2018; Accepted 27 June 2018; Published 7 August 2018

Academic Editor: Marta Fernández-García

Copyright (c) 2018 Min Chao. This is an open access article distributed under the Creative Commons Attribution License, which permits unrestricted use, distribution, and reproduction in any medium, provided the original work is properly cited.

A series of polyimides (PI) containing bridged linkages were prepared successfully through a three-step technique. The results indicated that the glass transition temperature $\left(T_{\mathrm{g}}\right)$ of polyimides was affected by flexibility of polymer chain and the intermolecular interactions. ODPA-TPER-based polyimide possesses the lowest $T_{\mathrm{g}}$, which was $214^{\circ} \mathrm{C}$. All polyimides had semicrystalline characteristics, and ODPA-TPER-based PI exhibited the lowest melting temperature $\left(T_{\mathrm{m}}\right)$ at $316^{\circ} \mathrm{C}$. The polyimides had high weight loss temperatures, which indicated that bridged linkages can reduce the softening temperature, meanwhile keeping excellent thermal stability.

\section{Introduction}

Polyimides (PI), as a kind of high-performance aromatic polymers, have found various applications in the aerospace and electronics industries, due to their excellent thermal stability and good mechanical and electrical properties [1-6]. But common polyimides, synthesized by pyromellitic dianhydride and diaminodiphenyl ether, could easily form charge-transfer complex among monomeric units to enhance the intermolecular force, which makes the polyimide features high glass transition temperature $\left(T_{\mathrm{g}}\right)$ and high melting temperature $\left(T_{\mathrm{m}}\right)$. Sometimes, the $T_{\mathrm{g}}$ and $T_{\mathrm{m}}$ cannot even be observed before the decomposition temperature $\left(T_{d}\right)$ is achieved [7-10]. This problem narrows the processing temperature range and influences the processability and applications of polyimides. An alternative strategy is to make structural changes based on the understanding that the superior performance of polyimide materials is mainly attributed to the structures of polymer chains. Very tiny changes in the chemical structures of the reaction monomers may have critical effects on the overall properties of the resulting PI [11-14]. For instance, introducing flexible links, bulky substituents, fluorinated groups, and copolymerization can improve the processability of polyimides without sacrificing the excellent thermal stability [15-24]. Among these approaches, introduction of bridged linkages into anhydride structure has been considered to be the most efficient one, which can not only provide broader processing temperature range but also retain thermal stability $[25,26]$.

The presence of crystalline components in materials has obvious influence on the properties of polymer [27, 28]. Semicrystalline polymers can be processed via a variety of processing methods. At the same time, crystalline regions play an important role like physical crosslinking does, maintaining polymer mechanical properties at certain level, even above its $T_{\mathrm{g}}$. Thus, research on the crystalline polyimide is highly valuable $[29,30]$.

In this article, the semicrystalline polyimides containing bridged linkages were synthesized using different monomers, and their properties were characterized. 
<smiles>O=C(c1ccc2c(c1)C(=O)OC2=O)c1ccc2c(c1)C(=O)OC2=O</smiles>

BTDA<smiles>O=C1OC(=O)c2cc(Oc3ccc4c(c3)C(=O)OC4=O)ccc21</smiles>

ODPA

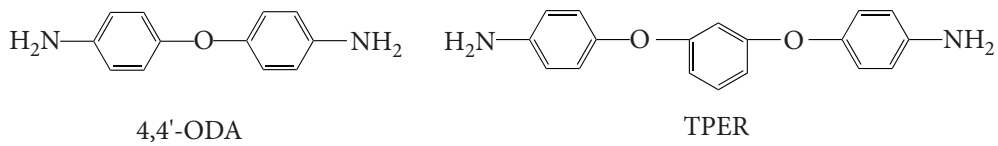

FIGURE 1: Chemical structure of monomers used for polyimide synthesis.<smiles>Nc1ccc(Oc2cccc(Oc3ccc(N)cc3)c2)cc1</smiles>

BTDA TPER<smiles>CC(C)[C@H]1CC[C@H](C)C1</smiles>
PAA

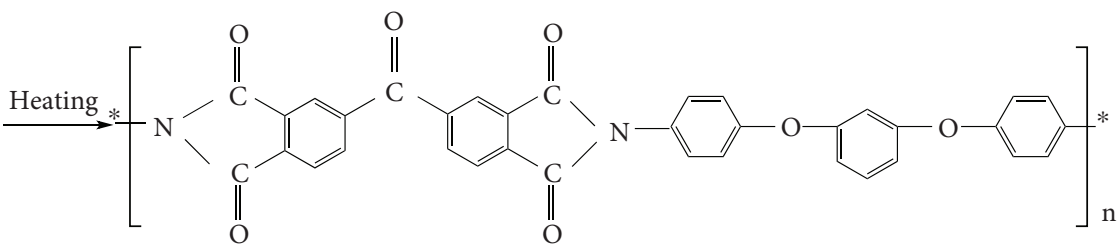

PI

Scheme 1: Preparation of BTDA-TPER PI.

\section{Experimental}

2.1. Starting Materials. 1,3-Bis(4-aminophenoxy)benzene (TPER) was synthesized in our laboratory. Benzophenonetetracarboxylic dianhydride (BTDA), oxydiphthalic anhydride (ODPA), 4,4'-diaminodiphenyl (ODA) were obtained from Sinopharm Chemical Reagent Co. Ltd. and used after recrystallization. N, ${ }^{\prime}$-dimethylacetamide (DMAc), methanol, and xylene were received from Tianjin Kermel Chemical Reagent Co. Ltd.

2.2. Polyimide Synthesis. Chemical structures of monomers used for polyimide synthesis were shown in Figure 1. The polyimide powder was synthesized from the diamine and dianhydride via a three-step technique. The synthesis of PI1 (BTDA-TPER) was used as an example to illustrate the procedure of polyimide synthesis as shown in Scheme 1. The first step is called poly(amide acid)-forming reaction. A threeneck flask equipped with a mechanical stirrer, a thermometer, and a water separator was used as the reaction vessel. TPER was added to the reaction vessel, followed by the addition of DMAc to achieve a $15 \%$ solid concentration. After the solution was stirred for 30 minutes, BTDA was added gradually in $2 \mathrm{~h}$ and then kept stirred for another $1 \mathrm{~h}$ to obtain poly(amide acid) (PAA). The second step goes through the solution imidization process, where xylene was added to the as-produced PAA mixture, which was heated to $140^{\circ} \mathrm{C}$ for $4 \mathrm{~h}$ to remove water. After cooling down, methanol was 
TABLE 1: Thermal properties of synthesized polyimides.

\begin{tabular}{|c|c|c|c|}
\hline & Monomer content (Mol) & $T_{\mathrm{g}}\left({ }^{\circ} \mathrm{C}\right)$ & $T_{\mathrm{m}}\left({ }^{\circ} \mathrm{C}\right)$ \\
\hline BTDA-TPER & $1.02: 1$ & 240 & 370 \\
\hline BTDA-ODA & $1.02: 1$ & 279 & 413 \\
\hline ODPA-TPER & $1.02: 1$ & 214 & 316 \\
\hline ODPA-ODA & $1.02: 1$ & 259 & 367 \\
\hline
\end{tabular}

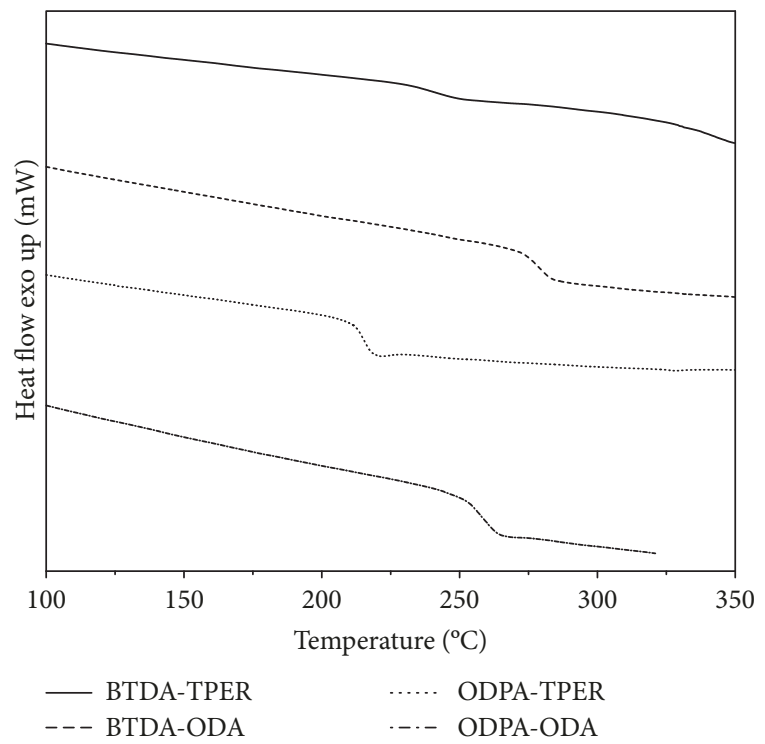

FIgURE 2: Glass transition curves of PI.

added, and the precipitated yellow polyimide powder was collected by filtration; this polyimide powder was partly imidized. And the last step will be the solid-phase thermal imidization to get fully imidized polyimide. In a forced air oven, the powder was kept at $100^{\circ} \mathrm{C}, 200^{\circ} \mathrm{C}$, and $300^{\circ} \mathrm{C}$ for $1 \mathrm{~h}$, respectively, to produce fully imidized polyimides as the final products. PI2 (BTDA-ODA), PI3 (ODPA-TPER), and PI4 (ODPA-ODA) were synthesized by the similar approach described above.

2.3. Characterization. Differential scanning calorimetry (DSC) measurement was performed on a TA Q1000-DSC under nitrogen atmosphere. Wide-angle X-ray diffraction (WXRD) measurement was conducted on an X'Pert MPD PRO X-ray diffractometer. The X-ray diffractometer was operated at $40 \mathrm{kV}$ and $35 \mathrm{~mA}$ using nickel-filtered $\mathrm{Cu} \mathrm{K} \alpha 1$ radiation. Results were collected during a continuous scan at a speed of $0.1^{\circ} / \mathrm{s}$ and step of $0.02^{\circ}$ between the angles of $5-70^{\circ}$. The morphology of the powder was characterized using a Quanta 200 environmental scanning electron microscope (SEM) of the FEI Company. The surfaces were sputter coated with a very thin layer of gold (approximately $15 \mathrm{~nm}$ thick) to prevent charging during imaging. Thermogravimetric analysis (TGA) was carried out on a Netzsch STA 449Ctype thermogravimetric analyzer at a heating rate of $5^{\circ} \mathrm{C} /$ min under nitrogen and air atmosphere, respectively.

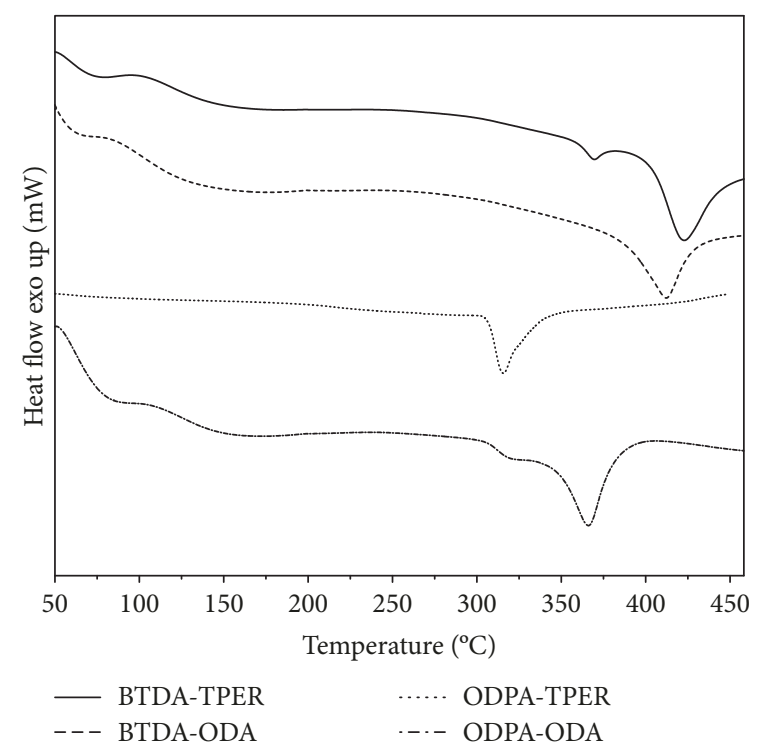

Figure 3: Melting curves of PI.

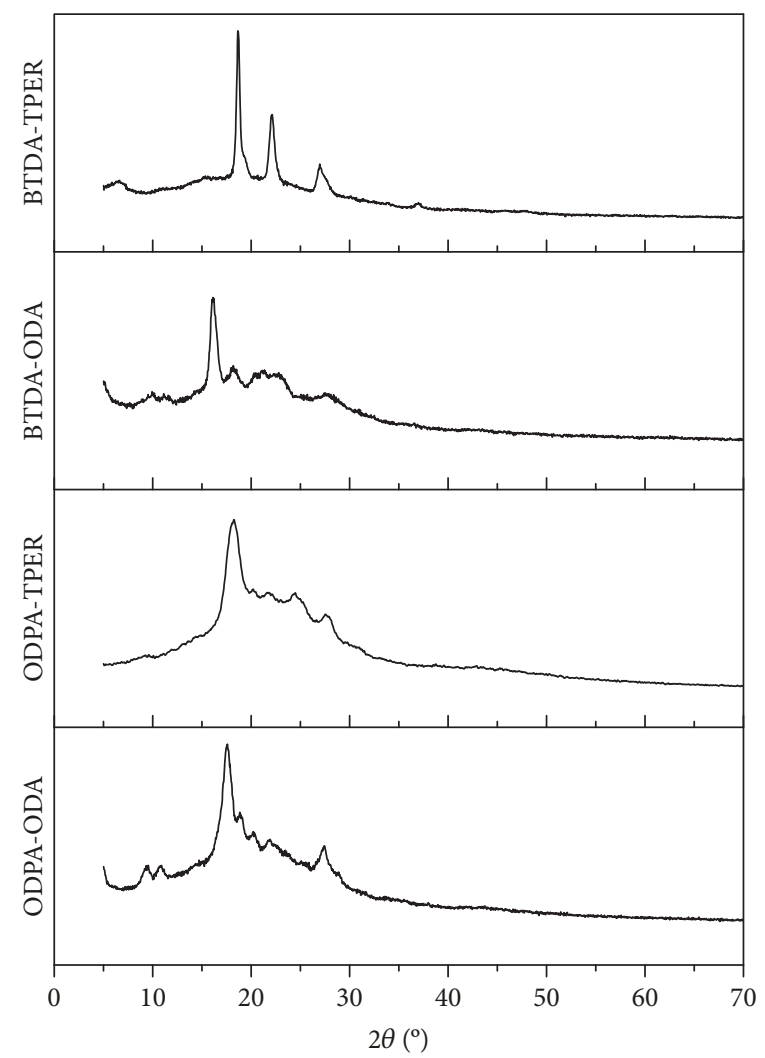

FIGURE 4: XRD patterns of polyimides.

\section{Results and Discussion}

The thermal properties of polyimides are shown in Table 1. DSC experiments were conducted by heating the polyimides to $400^{\circ} \mathrm{C}$ at $10^{\circ} \mathrm{C} / \mathrm{min}$, holding for $1 \mathrm{~min}$, quenching to $100^{\circ} \mathrm{C}$, and reheating at $10^{\circ} \mathrm{C} / \mathrm{min}$ to get the $T_{\mathrm{g}}$ 
TABLE 2: XRD parameters of polyimides.

\begin{tabular}{llccccccc}
\hline \multirow{2}{*}{ BTDA-TPER PI } & $2 \theta\left(^{\circ}\right)$ & 6.631 & 15.347 & 18.649 & 22.143 & 26.964 & 27.619 & 36.992 \\
& $d(\AA)$ & 13.3182 & 5.7688 & 4.7540 & 4.0112 & 3.3040 & 3.2241 & 2.4281 \\
BTDA-ODA PI & $2 \theta\left(^{\circ}\right)$ & 9.538 & 9.965 & 11.153 & 16.138 & 18.153 & 21.087 & 22.804 \\
& $d(\AA)$ & 9.2650 & 8.8687 & 7.9266 & 5.4878 & 4.8829 & 4.2096 & 3.8963 \\
ODPA-TPER PI & $2 \theta\left(^{\circ}\right)$ & 9.241 & 18.250 & 20.195 & 21.618 & 24.486 & 27.950 & 45.272 \\
& $d(\AA)$ & 9.5617 & 4.8571 & 4.3936 & 4.1075 & 3.6324 & 3.1896 & 2.0014 \\
ODPA-ODA PI & $2 \theta\left(^{\circ}\right)$ & 9.533 & 10.889 & 17.589 & 18.875 & 20.224 & 21.913 & 27.425 \\
& $d(\AA)$ & 9.2695 & 8.1185 & 5.0381 & 4.6976 & 4.3871 & 4.0528 & 3.2495 \\
\hline
\end{tabular}
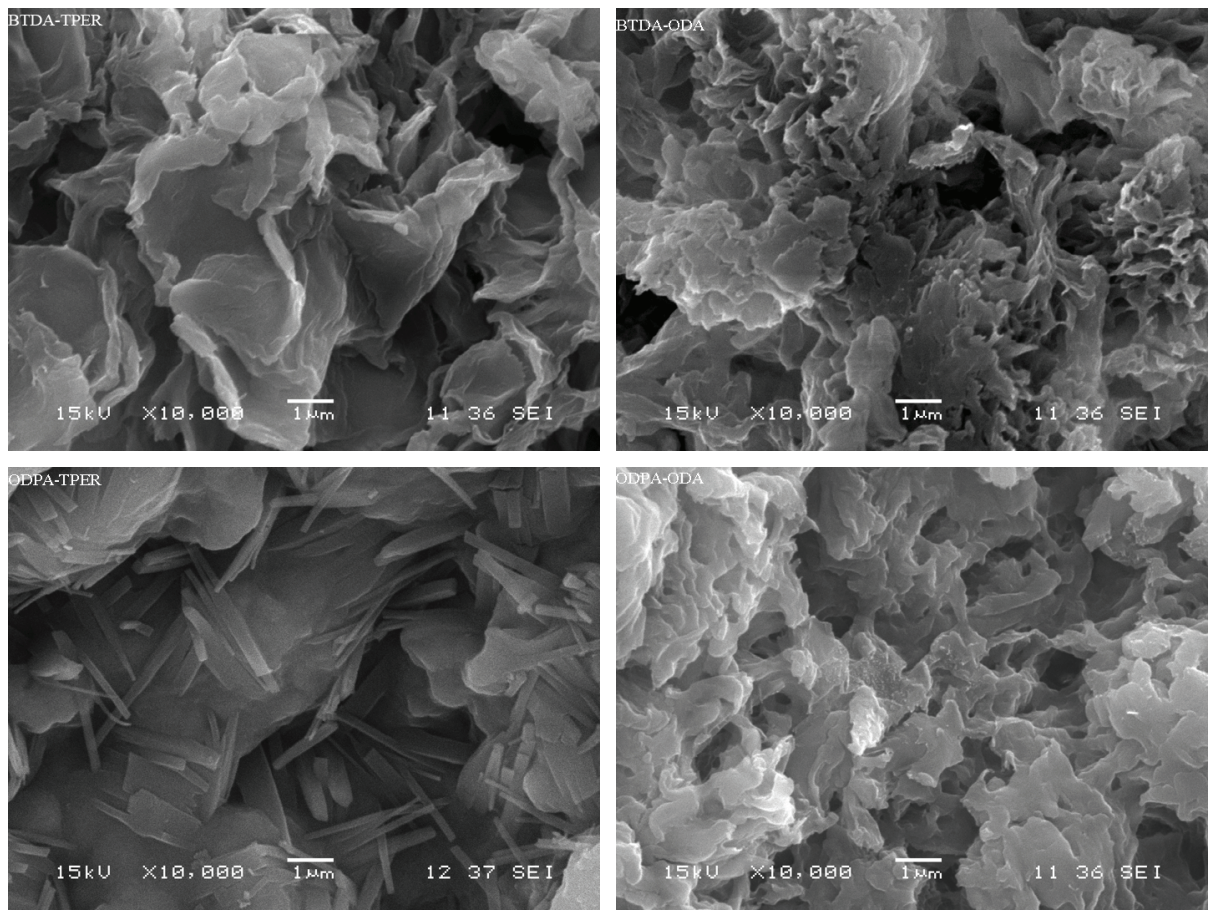

FIGURE 5: SEM images of polyimides.

(Figure 2). And $T_{\mathrm{m}}$ was obtained by heating the polyimides to $450^{\circ} \mathrm{C}$ at $10^{\circ} \mathrm{C} / \mathrm{min}$ (Figure 3 ).

$T_{\mathrm{g}}$ is mainly affected by the flexibility of polymer chain and the intermolecular interaction. Because of the symmetry of the benzene ring and the rotation of the benzene ring around the $\mathrm{C}-\mathrm{X}$ bond could be considered as free rotation, so the flexibility of polyimide only depends on the length of rigid chain and the valence angle of the $\mathrm{C}-\mathrm{X}-\mathrm{C}$ bond [31]. And the intermolecular interaction is dependent on the polarity of polar groups. Compared with $4,4^{\prime}$-ODA, TPER is more flexible. Since the valence angle of C-O-C is $123^{\circ}$, and the valence angle of $\mathrm{C}-\mathrm{CO}-\mathrm{C}$ is $127^{\circ}$, BTDA is slightly more flexible than ODPA. But the polarity of - $\mathrm{CO}-$ is stronger than that of -O-, so BTDA-based polyimide has stronger intermolecular interaction than ODPA-based polyimide. Affected by these two factors, ODPA-TPER-based polyimide showed the lowest $T_{\mathrm{g}}$ due to the most flexible chain, which was $214^{\circ} \mathrm{C}$. And the BTDA-ODA-based polyimide showed the highest value at $279^{\circ} \mathrm{C}$.
Regarding the melting temperature, $T_{\mathrm{m}}$ had more influencing factors than $T_{\mathrm{g}}$; it could also be influenced by the crystal perfection and the lamellar thickness. The values of $T_{\mathrm{m}}$ had similar trend to the $T_{\mathrm{g}}$ values. ODPA-TPER PI showed the lowest value, which was $316^{\circ} \mathrm{C}$. BTDA-ODA PI showed the highest value, which was $413^{\circ} \mathrm{C}$. In addition, BTDA-TPER PI showed two obvious $T_{\mathrm{m}}$ peaks; it was because the polyimide recrystallized after the first crystallization. And the recrystallization made the crystal more perfect than before, so the second $T_{\mathrm{m}}$ value was higher, which was $424^{\circ} \mathrm{C}$.

It can be found from the $T_{\mathrm{g}}$ and $T_{\mathrm{m}}$ results that all of the four polyimides containing bridged linkages have measurable $T_{\mathrm{g}}$ and low $T_{\mathrm{m}}$, so can be expected to be appropriate for many different types of processing methods, and have lower requirement for the equipment. At the same time, the $T_{\mathrm{g}}$ of the polyimides is high enough to be used at a high temperature without losing its mechanical properties and lower than the decomposition temperature, $T_{\mathrm{d}}$, to make the polyimides suitable for processing. 


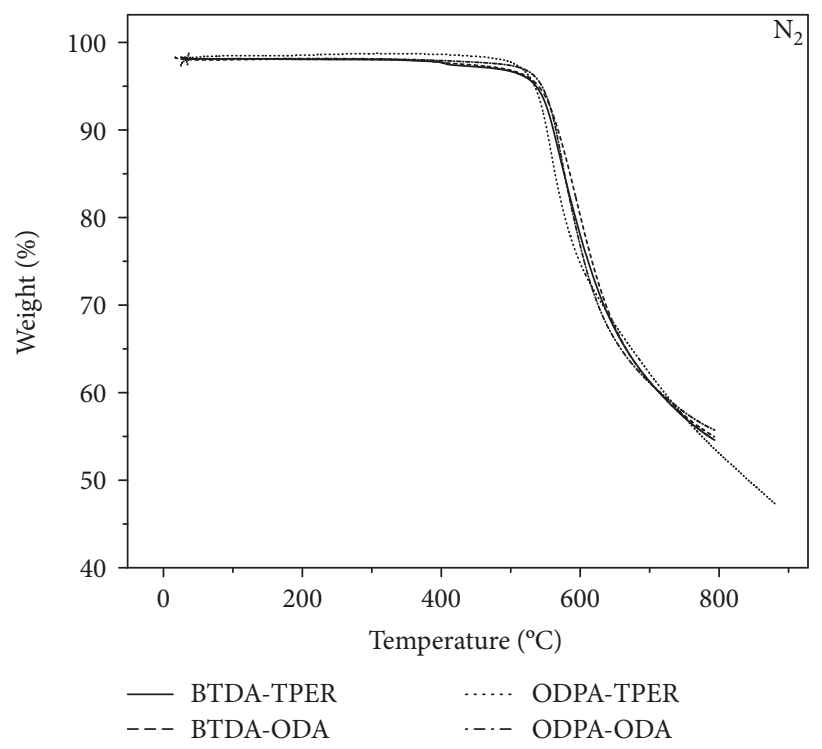

(a)

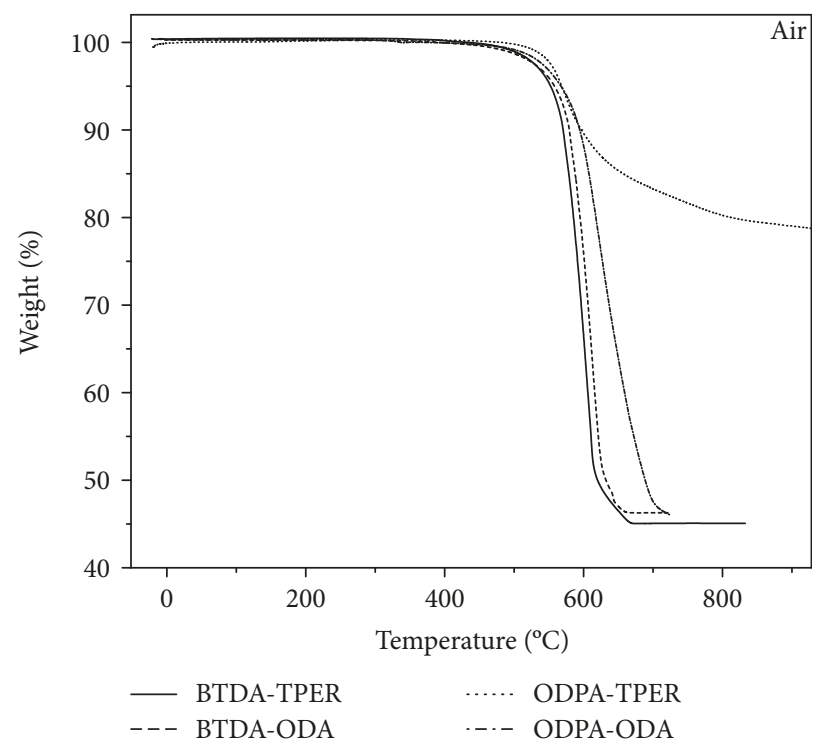

(b)

FIGURE 6: TGA curves of polyimide.

The XRD patterns and the corresponding parameters are given in Figure 4 and Table 2. In the XRD pattern, obvious diffraction peaks in crystalline fields and dispersion peaks in the amorphous region, which suggested different types of polyimides had semicrystalline phase, although they possess diffraction peaks at different positions. For example, BTDA-TPER PI exhibited three strong reflections at $18^{\circ}$, $22^{\circ}$, and $26^{\circ}$; BTDA-ODA PI showed peaks at $10^{\circ}, 16^{\circ}, 18^{\circ}$, and $21^{\circ}$; and ODPA-TPER had a strong reflection peak at $18^{\circ}$. This phenomenon was because these four polyimides had different crystal structures due to the difference of their molecular chains.

The morphologies of polyimides were characterized by SEM (Figure 5). The result indicated that four polyimides showed various crystalline phases, that is, BTDA-TPER PI showed disorderly folds formed from thick-flake crystal structure, while BTDA-ODA PI looked like flowers which grew from thin flake crystal. ODPA-TPER PI had a large amount of well-ordered thin flake crystal, and ODPA-ODA PI displayed an irregular coral structure which formed from a flake crystal of different sizes and thicknesses. The morphologies of polymers depended upon the chain packing of polymer chains during the crystallization growth. And the chain packing was strongly influenced by the flexibility of polyimides. So the differences of flexibility of four polyimides gave them various crystalline phases and different $T_{\mathrm{m}}$.

The weight loss temperatures of the polyimides under nitrogen and air atmospheres were measured by the TGA (Figure 6 and Table 3). It could be found from the results that polyimides showed excellent thermal stability; the 5\% weight loss temperatures under nitrogen and air atmosphere were above $555^{\circ} \mathrm{C}$ and $530^{\circ} \mathrm{C}$, respectively. But the differences of four polyimides were not distinctive. Compare two kinds of anhydride; the ketone that unites in the BTDA polyimides could decarbonylate to form a biphenyl structure and
TABLE 3: Weight loss temperatures of polyimides.

\begin{tabular}{lcccc}
\hline & \multicolumn{2}{c}{$T_{5 \%}\left({ }^{\circ} \mathrm{C}\right)$} & \multicolumn{2}{c}{$T_{10 \%}\left({ }^{\circ} \mathrm{C}\right)$} \\
& $\mathrm{N}_{2}$ & AIR & $\mathrm{N}_{2}$ & AIR \\
\hline BTDA-TPER PI & 562 & 531 & 580 & 555 \\
BTDA-ODA PI & 566 & 531 & 588 & 560 \\
ODPA-TPER PI & 555 & 553 & 569 & 570 \\
ODPA-ODA PI & 567 & 541 & 583 & 569 \\
\hline
\end{tabular}

maintain its thermal stability, so their weight loss temperatures are higher. And compare two diamines; TPER polyimides have ether bond between the benzene rings, which are a weakness to thermal stability, so their weight loss temperatures are lower.

\section{Conclusion}

In summary, four polyimide powders based on BTDA and ODPA were prepared successfully through a three-step technique, and their properties were studied. The DSC results showed that all of the polyimides had measurable $T_{\mathrm{g}}$ and low $T_{\mathrm{m}}$, affected by flexibility of the polymer chain and the intermolecular interaction, that is, ODPA-TPER PI had the lowest $T_{\mathrm{g}}$, which was $214^{\circ} \mathrm{C}$. All of the polyimides had semicrystalline characters but various crystalline morphologies and different $T_{\mathrm{m}}$, due to their different molecular structures, for instance, ODPA-TPER PI exhibited the lowest $T_{\mathrm{m}}-316^{\circ} \mathrm{C}$. At the same time, polyimides still retained high weight loss temperatures; all of their $T_{5 \%}$ are above $550^{\circ} \mathrm{C}$, which indicated that bridged linkages can reduce the $T_{\mathrm{g}}$ and $T_{\mathrm{m}}$, meanwhile keeping excellent thermal stability. 


\section{Data Availability}

The data used to support the findings of this study are available from the corresponding author upon request.

\section{Conflicts of Interest}

The author declares that there are no conflicts of interest.

\section{Acknowledgments}

The author disclosed receipt of the following financial support for the research, authorship, and/or publication of this article: this work was supported by funding from the Natural Science Basic Research Plan in Shaanxi Province of China (Grant no. 2016JQ5099).

\section{References}

[1] N. A. Adrova, M. I. Bessonov, L. A. Laius, and A. P. Rudakov, Polyimides (a New Class of Thermally Stable Polymers), Technomic Publishing Co, Stanford, 1970.

[2] J.-H. Kim, H.-N. Jang, and J.-Y. Lee, "Preparation of novel polyimides with high thermal stability of dipole alignment for electro-optic applications," Polymer Bulletin, vol. 60, no. 2-3, pp. 181-189, 2008.

[3] S. H. Zhang, X. Y. Li, X. X. Guan et al., "Synthesis of pyridinecontaining diamine and properties of its polyimides and polyimide/hexagonal boron nitride composite films," Composites Science and Technology, vol. 152, pp. 165-172, 2017.

[4] D. A. Patterson, A. Havill, S. Costello, Y. H. See-Toh, A. G. Livingston, and A. Turner, "Membrane characterisation by SEM, TEM and ESEM: the implications of dry and wetted microstructure on mass transfer through integrally skinned polyimide nanofiltration membranes," Separation and Purification Methods, vol. 66, no. 1, pp. 90-97, 2009.

[5] K.-M. Ting, J. Xu, and B.-H. Guo, "A novel vacuum-assisted method for fabricating flexible polyimide foams from $3,3^{\prime}, 4,4^{\prime}$-oxydiphthalic anhydride/4,4'-oxydianiline," High Performance Polymers, vol. 29, no. 3, pp. 272-278, 2016.

[6] H. Moghanian, A. Mobinikhaledi, and Z. Baharangiz, "Synthesis, characterization and magnetic properties of novel heat resistant polyimide nanocomposites derived from $14 \mathrm{H}$-dibenzo $[\mathrm{a}, \mathrm{j}]$ xanthene," Journal of Polymer Research, vol. 21, no. 7, pp. 513-529, 2014.

[7] M. I. Bessonov and V. A. Zubkov, Polyamic Acids and Polyimides: Synthesis, Transformations, and Structure, CRC Press, 1993.

[8] J. Q. Zhang, H. X. Gao, T. Z. Ji et al., "Synthesis and thermal behaviors of 1,3-bis(4-aminophenoxy)benzene (TPER) and polyimide based on TPER and pyromellitic dianhydride," Journal of Thermal Analysis and Calorimetry, vol. 114, no. 1, pp. 441-449, 2013.

[9] R. V. Ghorpade, A. K. Thorave, C. R. Rajan, N. N. Chavan, and S. Ponrathnam, "Synthesis and characterization of thermally stable polyimides with a pendent phenothiazine unit based on new diamine 10-(3,5-diaminobenzoyl)phenothiazine," High Performance Polymers, vol. 28, no. 1, pp. 26-33, 2016.

[10] K. Kim, T. Yoo, J. Lee et al., "The effects of hydroxyl groups on the thermal and optical properties of poly(amide-imide)s with high adhesion for transparent films," Progress in Organic Coating, vol. 112, pp. 37-43, 2017.
[11] S. Y. Liu, S. Y. Zhu, X. P. Wang, H. Tan, and S. Guan, "Synthesis and properties of $(\mathrm{A} 2+\mathrm{B} 4)$-type hyperbranched polyimides with different terminal groups," High Performance Polymers, vol. 29, no. 1, pp. 46-57, 2017.

[12] P. Yu, Y. Wang, J. R. Yu, J. Zhu, and Z. M. Hu, "Synthesis and characterization of phenylethynyl-terminated polyimide oligomers derived from 2,3,3,4-diphenyl ether tetracarboxylic acid dianhydride and 3,4'-oxydianiline," Chinese Journal of Polymer Science, vol. 34, no. 1, pp. 122-134, 2016.

[13] J. Li, G. Zhang, Q. Zhu, J. Li, H. Zhang, and Z. Jing, "Synthesis and properties of ultralow dielectric constant porous polyimide films containing trifluoromethyl groups," Journal of Applied Polymer Science, vol. 134, no. 8, 2017.

[14] S. Ando, Y. Koyama, S. Miyata, S. Sato, S. Kanehashi, and K. Nagai, "Synthesis and characterization of ABA-type triblock copolymers derived from polyimide and poly (2-methyl-2-adamantyl methacrylate)," Polymer International, vol. 63, no. 9, pp. 1634-1642, 2014.

[15] M. A. Abdulhamid, X. Ma, X. Miao, and I. Pinnau, "Synthesis and characterization of a microporous 6FDA-polyimide made from a novel carbocyclic pseudo Tröger's base diamine: effect of bicyclic bridge on gas transport properties," Polymer, vol. 130, pp. 182-190, 2017.

[16] N. Alaslai, X. Ma, B. Ghanem, Y. Wang, F. Alghunaimi, and I. Pinnau, "Synthesis and characterization of a novel microporous dihydroxyl-functionalized triptycene-diamine-based polyimide for natural gas membrane separation," Macromolecular Rapid Communications, vol. 38, no. 18, 2017.

[17] J. W. Li, G. C. Zhang, Z. X. Jing, J. Li, L. Zhou, and H. Zhang, "Synthesis and characterization of porous polyimide films containing benzimidazole moieties," High Performance Polymers, vol. 29, no. 7, pp. 869-876, 2017.

[18] T. Ryu, S. C. Sutradhar, F. Ahmed et al., "Synthesis and characterization of sulfonated mutiphenyl conjugated polyimide for PEMFC," Journal of Industrial and Engineering Chemistry, vol. 49, pp. 99-104, 2017.

[19] A. K. Mandal, S. Bisoi, S. Banerjee, H. Komber, and B. Voit, "Sulfonated copolyimides containing trifluoromethyl and phosphine oxide moieties: synergistic effect towards proton exchange membrane properties," European Polymer Journal, vol. 95, pp. 581-595, 2017.

[20] A. Feyzi, K. Faghihi, and A. A. Zolanvari, "Synthesis and characterization of new polyimide/organoclay nanocomposites derived from 3,3'4,4'-biphenyltetracarboxylic dianhydride and 1,2-bis(4-aminophenoxy) ethane," High Temperature Materials and Processes, vol. 32, no. 2, 2013.

[21] Y. Chen, R. Huang, Q. Zhang, W. Sun, and X. Liu, "Synthesis and properties of highly soluble branched polyimide based on 2,4,6-triaminopyrimidine," High Performance Polymers, vol. 29, no. 1, pp. 68-76, 2017.

[22] D. H. Lee, H. Yeo, G. R. Kim et al., "Synthesis and preparation of alkyl-functionalized graphene oxide/polyimide nanocomposites," Macromolecular Research, vol. 22, no. 12, pp. 13441347, 2014.

[23] S. H. Hsiao and K. H. Lin, "Synthesis and properties of electroactive aromatic polyimides with methyl- or trifluoromethylprotecting triphenylamine units," High Performance Polymers, vol. 29, no. 5, pp. 544-555, 2016.

[24] X. D. Ji, J. L. Yan, X. J. Liu, Z. Wang, and Z. Wang, "Synthesis and properties of polyimides derived from bis(4-aminopheny1)isohexides," High Performance Polymers, vol. 29, no. 2, pp. 197-204, 2017. 
[25] M. Fryd, Structure-Tg Relationship in Polyimides (Glass Transition Temperature) in Polyimides: Synthesis, Characterization, and Applications, Plenum Press, New York, 1984.

[26] L. M. Kash, Polyimides and Other High Temperature Polymers: Synthesis, Characterization and Applications, Volume 1, Book, 2001.

[27] D. C. Bassett, A. Keller, and S. Mitsuhashi, "New features in polymer crystal growth from concentrated solutions," Journal of Polymer Science Part A: General Papers, vol. 1, no. 2, pp. 763-788, 1963.

[28] H. G. Philip, Polymer Singer Crystals, Interscience Wiley, New York, 1963.

[29] S. L. Liu, T. S. Chung, H. Oikawa, and A. Yamaguchi, "The double melting behavior of a liquid crystalline polyimide derived from PMDA and 1,3-bis[4-(4'-aminophenoxyl) cumyl] benzene," Journal of Polymer Science Part B: Polymer Physics, vol. 38, no. 23, pp. 3018-3031, 2000.

[30] S. L. Liu, T. S. Chung, L. Lu, Y. Torii, H. Oikawa, and A. Yamaguchi, "Crystallization kinetics of a thermotropic liquid crystalline polyimide derived from 1,3-bis[4-(4'-aminophenoxyl) cumyl] benzene," Journal of Polymer Science Part B: Polymer Physics, vol. 36, no. 10, pp. 1679-1694, 1998.

[31] S. A. Pavlova, G. I. Timofeyeva, V. V. Korshak, Y. S. Vygodskii, S. V. Vinogradova, and N. A. Churochkina, "The hydrodynamic properties of the polyimide from the dianhydride of 3,4,3',4'-tetracarboxydiphenyl oxide and 9, 9-bis-(4-aminophenyl) fluorene," Polymer Science U.S.S.R, vol. 15, no. 12, pp. 3008-3015, 1973. 


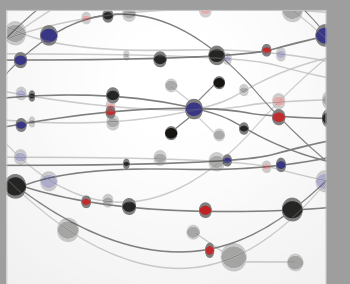

The Scientific World Journal
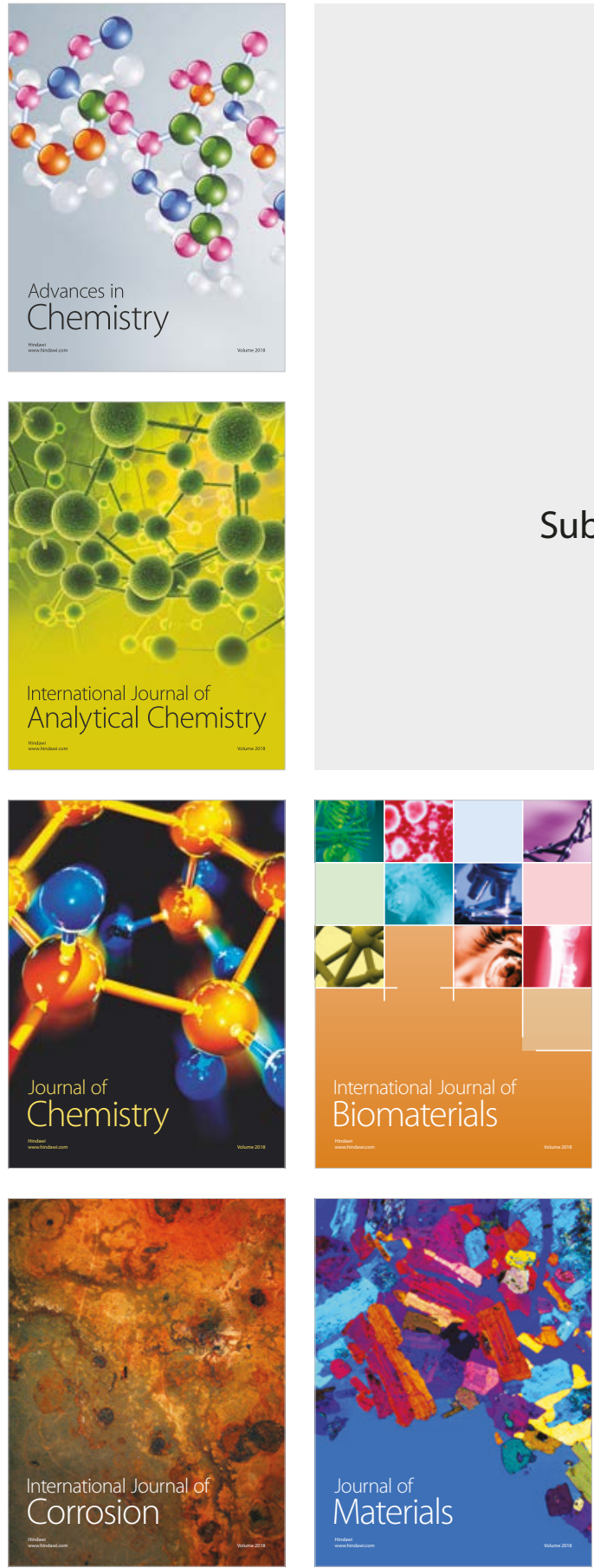

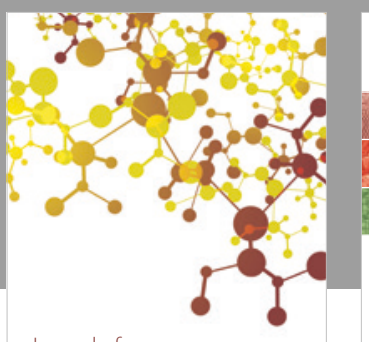

Journal of

Applied Chemistry
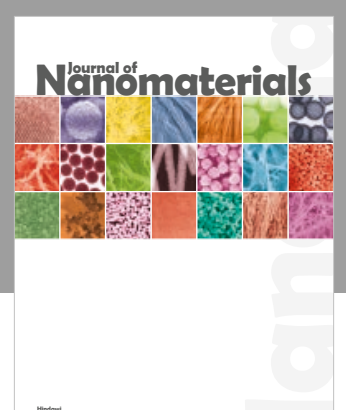

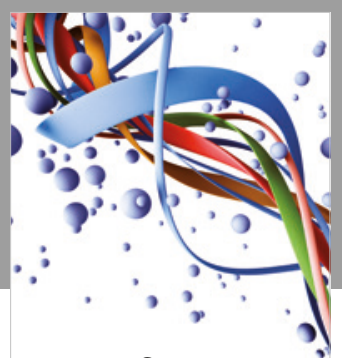

Scientifica

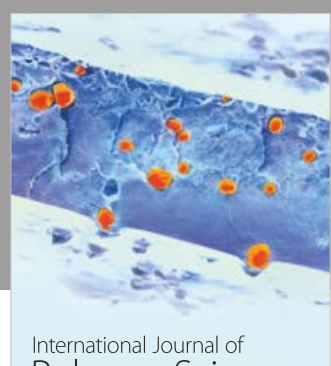

Polymer Science

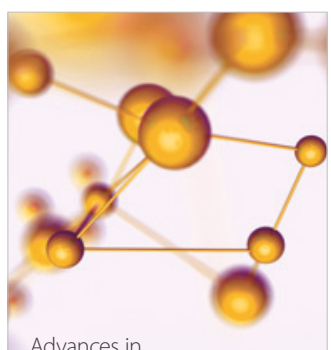

Physical Chemistry
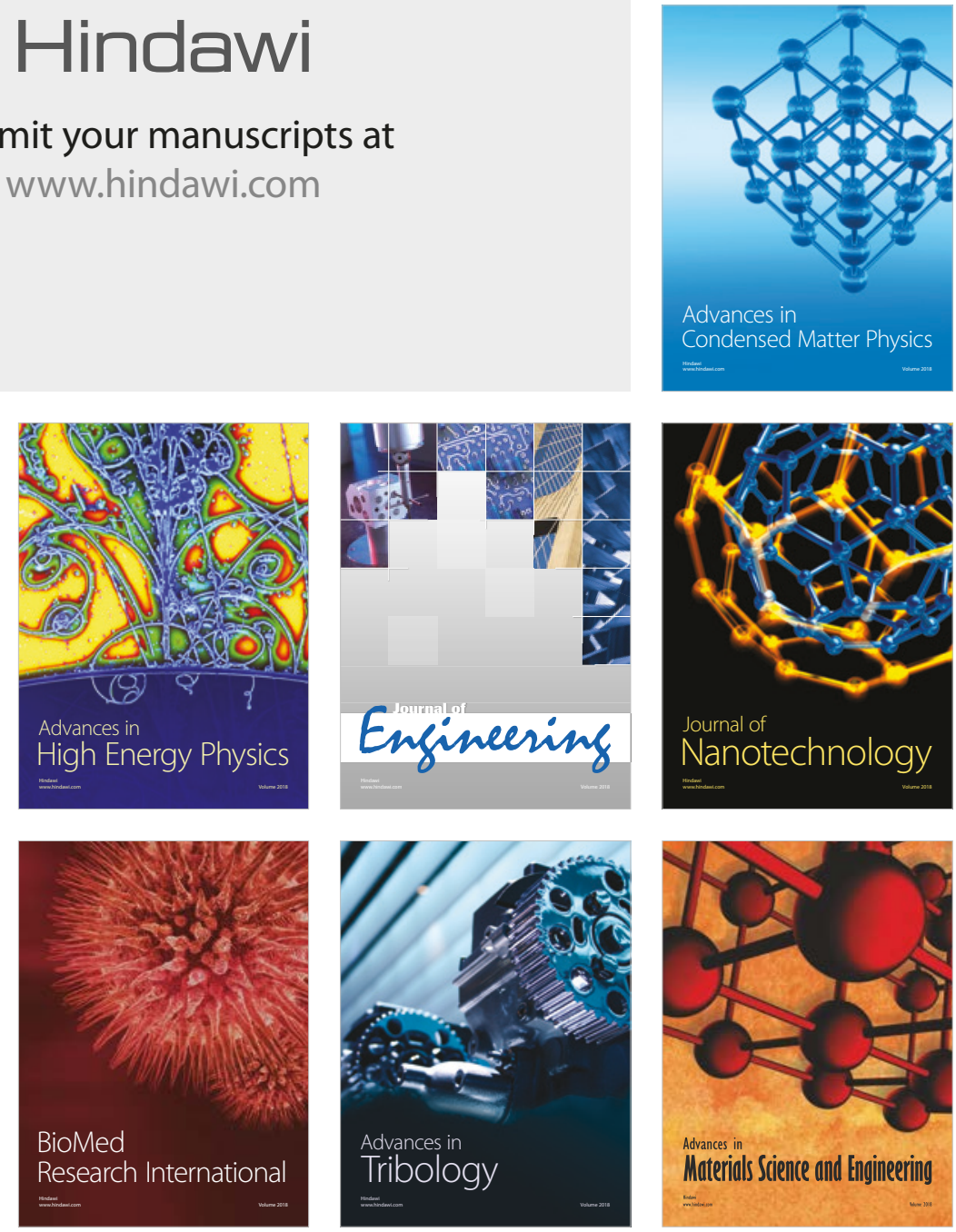